\section{Molecular and Cellular Biology}

Differential distribution of factors involved in pre-mRNA processing in the yeast cell nucleus.

J A Potashkin, R J Derby and D L Spector

Mol. Cell. Biol. 1990, 10(7):3524. DOI: 10.1128/MCB.10.7.3524.

Updated information and services can be found at:

http://mcb.asm.org/content/10/7/3524

These include:

CONTENT ALERTS

Receive: RSS Feeds, eTOCs, free email alerts (when new articles cite this article), more» 


\title{
Differential Distribution of Factors Involved in Pre-mRNA Processing in the Yeast Cell Nucleus
}

\author{
JUDITH A. POTASHKIN, † ROBERT J. DERBY, AND DAVID L. SPECTOR* \\ Cold Spring Harbor Laboratory, Cold Spring Harbor, New York 11724
}

Received 6 March 1990/Accepted 19 April 1990

\begin{abstract}
The yeast cell nucleus has previously been shown to be divided into two regions by a variety of microscopic approaches. We used antibodies specific for the 2,2,7-trimethylguanosine cap structure of small nuclear ribonucleic acids (snRNAs) and for a protein component of small nuclear ribonucleoprotein particles to identify the distribution of small nuclear ribonucleoprotein particles within the yeast cell nucleus. These studies were performed with the fission yeast Schizosaccharomyces pombe and the budding yeast Saccharomyces cerevisiae. By using immunofluorescence microscopy and immunoelectron microscopy, most of the abundant snRNAs were localized to the portion of the nucleus which has heretofore been referred to as the nucleolus. This distribution of snRNAs is different from that found in mammalian cells and suggests that the nucleolar portion of the yeast nucleus contains functional domains in addition to those associated with RNA polymerase I activity.
\end{abstract}

The nuclei of mammalian cells are organized into defined structural and functional domains. The domains which are readily visible by phase-contrast microscopy are the nucleoplasm and the nucleolus. Electron microscopic studies have shown that the nucleoplasm is composed of euchromatic and heterochromatic domains, as well as numerous fibrillar and granular components (for a review, see reference 4) about which little functional information is available. The interphase nucleolus is attached to the nuclear envelope (23) and is organized into three distinct regions: the fibrillar centers, the dense fibrillar component, and the granular component $(12,15,17)$. DNA emanating from the chromosomal nucleolus-organizing region extends into the nucleolus via the fibrillar center(s); the chromatin in these regions (fibrillar centers) of the nucleolus is transcriptionally inactive. Transcriptionally active chromatin is found in the fibrillar regions surrounding the fibrillar centers. The $80 \mathrm{~S}$ preribosomal particles accumulate in the granular region of the nucleolus.

In contrast to vertebrate nuclei, yeast nuclei are considerably smaller and appear to have less apparent internal structure. By phase-contrast microscopy, a dark, crescentshaped region is apparent on one side of the nucleus $(30,46)$. Electron microscopy has revealed that there are two readily distinguishable regions of a yeast nucleus; one electrondense region that occupies about one-third to one-half of the nucleus and a less electron-dense region $(16,30,31,45,46$, $50,56)$. DNase treatment of isolated nuclei, followed by electron microscopic examination, has suggested that the region of low electron density is composed of chromatin (31, 49). The chromatin region is uniform in appearance and cannot be easily divided into euchromatic and heterochromatic regions $(16,30,31,45,46,50,56)$. The electron-dense region of the nucleus has been referred to as the nucleolus on the basis of ultrastructural studies which have shown that this region contains morphological components which resemble the nucleolonema (fibrillar regions) seen in nucleoli of higher eucaryotes $(16,31,50,56)$. In addition, studies

\footnotetext{
* Corresponding author.

$\dagger$ Present address: Department of Pharmacology and Molecular Biology, University of Health Sciences/The Chicago Medical School, North Chicago, IL 60064.
}

have shown that this region is RNA and protein rich (31) and both the $37 \mathrm{~S}$ and $28 \mathrm{~S}$ rRNA precursors are located there (49, 50). In conventional transmission electron micrographs of the budding yeast Saccharomyces cerevisiae $(16,31,50)$ and the fission yeast Schizosaccharomyces pombe $(30,45)$, the nucleolar region which is attached to the nuclear envelope appears to lack any additional substructure. However, nuclei of the fission yeast Schizosaccharomyces japonicus var. versatilis show patches of low electron density within the nucleolar region (43). Similar regions of low electron density have been observed in transmission electron micrographs of $S$. pombe when the cells are fixed by the method of freezesubstitution (56). No function has been assigned to these regions of low electron density.

In addition to the classical morphological and biochemical studies, immunolabeling studies have been used to identify structural and functional subregions of the nucleus. Such an approach was used in mammalian cells to localize small nuclear ribonucleoprotein particles (snRNPs) $(34,42,52$, 53). In eucaryotes, there are six abundant small nuclear ribonucleic acids (snRNAs), referred to as U1 to U6, which are complexed with several polypeptides to form snRNPs (for a review, see reference 29). U1, U2, U4, U5, and U6 have been shown to be essential for pre-mRNA splicing (for a review, see reference 55). U3 is localized in the nucleolus $(5,38,41)$ and is most likely involved with rRNA processing $(11,38,41)$. All of the $U$ snRNAs, except for U6, have a 2,2,7-trimethylguanosine $\left(m_{3} G\right)$ cap structure at their $5^{\prime}$ ends. All of the snRNPs with which these snRNAs are associated are recognized by anti-Sm serum from individuals with certain autoimmune diseases, such as lupus erythematosus (33), except for U3, which is nucleolar (39). Anti-Sm antibodies $(27,33,34,48,51-54)$ and antibodies that recognize the $m_{3} G$ cap (42) have been used to localize snRNPs in mammalian cells. The particles are concentrated in clusters commonly referred to as speckles within the nonchromatincontaining region of the nucleoplasm (53). Recently, Fu and Maniatis (14) have shown that a splicing factor which is not a snRNP protein colocalizes to these speckled nuclear regions. A three-dimensional reconstruction of a mammalian cell nucleus by immunoelectron microscopy has revealed that this speckled pattern of snRNPs forms a reticular 

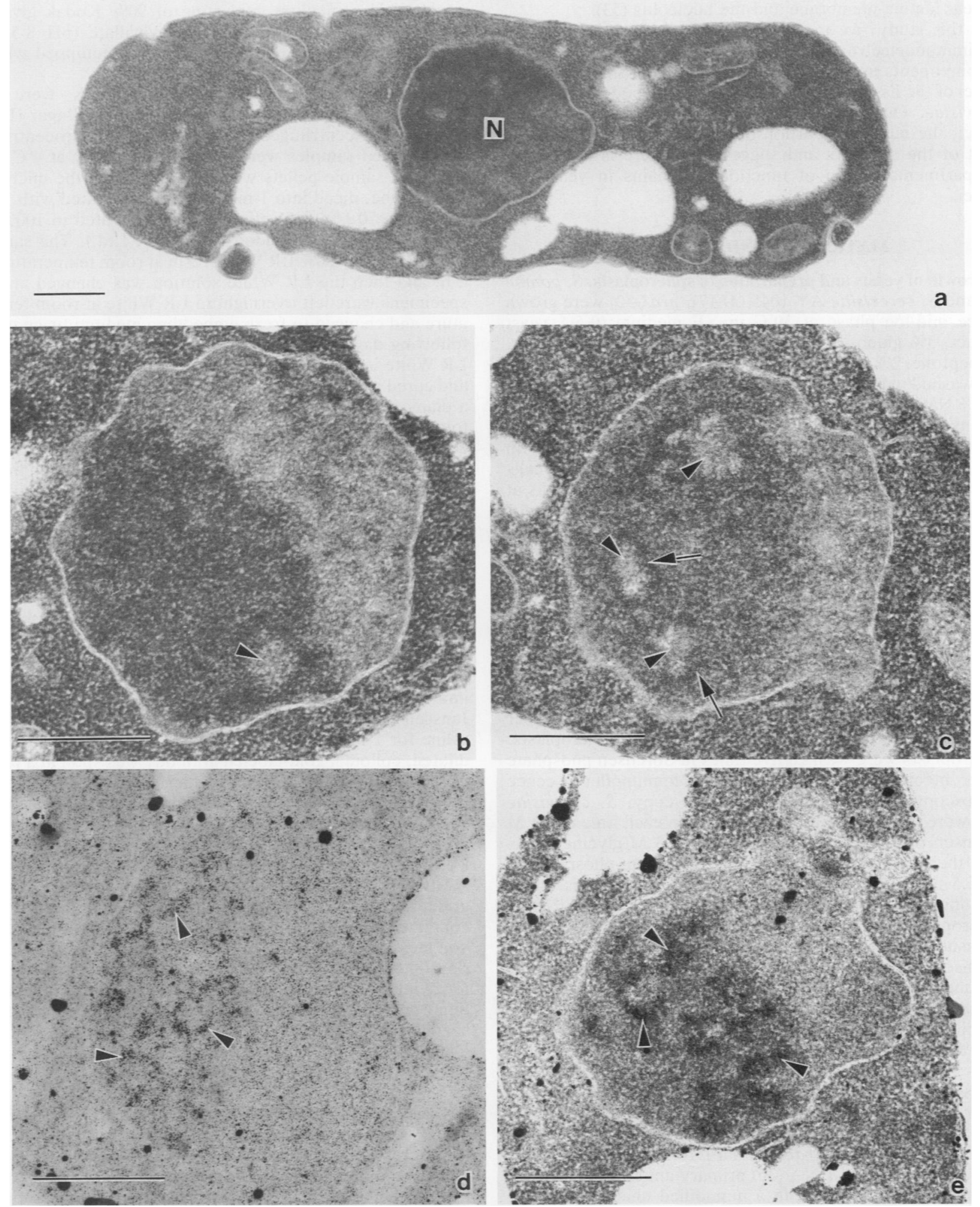

FIG. 1. Standard transmission electron micrograph of a cell section of $S$. pombe (a) showing the electron-dense and less electron-dense portions of the cell nucleus $(\mathrm{N})$. Within the electron-dense portion of the nucleus, irregularly shaped electron-lucid regions were visible (b and c, arrowheads). These regions resemble fibrillar centers of mammalian cell nucleoli. Usually, one to five such regions were seen in each cell section. Often these regions were surrounded by a region of greater electron density (c, arrows) which resembles the fibrillar component of mammalian cell nucleoli. Silver-stained cell sections revealed a densely staining latticework within one portion of the cell nucleus (d). When silver-stained sections were poststained with uranyl acetate and lead citrate, this latticework was observed to be localized within the nucleolar portion of the cell nucleus (e). The silver-stained regions often surrounded the less electron-dense fibrillar centers (e). Bars, $0.5 \mu \mathrm{m}$. 
network within the nucleoplasm, which extends between the nuclear lamina-membrane and the nucleolus (53).

In this study, we used immunofluorescense microscopy and immunoelectron microscopy to evaluate the localization of components involved in pre-mRNA processing within the nuclei of the fission yeast $S$. pombe and the budding yeast $S$. cerevisiae. Our results show that unlike mammalian cell nuclei, the nucleolar portion of the yeast nucleus contains most of the snRNAs and suggest that there is a different compartmentalization of functional domains in yeast cell nuclei.

\section{MATERIALS AND METHODS}

Growth of yeasts and preparation of spheroplasts. $S$. pombe

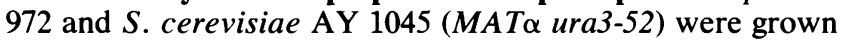
to the mid-log phase at $30^{\circ} \mathrm{C}$ in $\mathrm{YE}$ medium $(0.5 \%$ yeast extract, $3 \%$ glucose) and YPD medium (1\% yeast extract, $2 \%$ peptone, $2 \%$ glucose), respectively. Cells were harvested and washed in phosphate-buffered saline (PBS) $\left(10 \mathrm{mM} \mathrm{PO}_{4}\right.$, $0.85 \% \mathrm{NaCl}$ ) at $\mathrm{pH} 7.3$ for fluorescence microscopy or $0.1 \mathrm{M}$ Sorensen phosphate buffer at $\mathrm{pH} 5.6$ for electron microscopy. $S$. pombe cells were fixed for electron microscopy in Sorensen phosphate buffer at $\mathrm{pH} 5.6$, and $S$. cerevisiae cells were fixed in the same buffer at $\mathrm{pH} 6.0$ to keep the cells at the same $\mathrm{pH}$ as the medium in which they were grown for better preservation of the cellular ultrastructure. Cells were fixed for $1 \mathrm{~h}$ in $2 \%$ formaldehyde- $0.01 \%$ glutaraldehyde in PBS for fluorescence microscopy or $2 \%$ formaldehyde- $0.1 \%$ glutaraldehyde in Sorensen phosphate buffer for electron microscopy. Formaldehyde solutions were made fresh from paraformaldehyde. $S$. pombe cells were then washed three times in Sorensen phosphate buffer containing $0.3 \mathrm{M}$ glycine, harvested, suspended at a concentration of $10^{7} / \mathrm{ml}$ in $1.2 \mathrm{M}$ sorbitol-50 mM citrate-phosphate ( $\mathrm{pH}$ 5.6)-40 mM EDTA-1 $\mathrm{mM} \beta$-mercaptoethanol-1 mg of Novozyme (Novolab) per $\mathrm{ml}$, and incubated at $37^{\circ} \mathrm{C}$ for $1 \mathrm{~h}$ to prepare spheroplasts. Spheroplasts were washed five times in Sorensen phosphate buffer before further processing for immunofluorescence microscopy or immunoelectron microscopy. S. cerevisiae cells were washed three times for $10 \mathrm{~min}$ each time in $0.1 \mathrm{M}$ Sorensen phosphate buffer containing $0.3 \mathrm{M}$ glycine. Cells were then washed in $0.1 \mathrm{M}$ dibasic potassium phosphate at $\mathrm{pH} 6.5$ for $10 \mathrm{~min}$ and were then incubated in this buffer containing $0.1 \mathrm{mg}$ of Zymolyase per $\mathrm{ml}$ for $45 \mathrm{~min}$ at $30^{\circ} \mathrm{C}$. Spheroplasts were washed three times in $0.1 \mathrm{M}$ dibasic potassium phosphate, followed by three 10-min washes in Sorensen phosphate buffer before further processing for immunoelectron microscopy.

Immunofluorescence microscopy. Spheroplasts were permeabilized with $0.2 \%$ Triton X-100 in PBS (pH 7.3) containing $0.5 \%$ normal goat serum for $1 \mathrm{~min}$ and then washed three times in PBS containing $1 \%$ normal goat serum. Spheroplasts $(100 \mu \mathrm{l})$ were applied to a poly-L-lysine-coated glass cover slip, and the spheroplasts were allowed to attach for 15 min. The cover slip was washed for $10 \mathrm{~min}$ with PBS. The spheroplasts were incubated with a 1:10 dilution of anti- $\mathrm{m}_{3} \mathrm{G}$ (24), D77 (1), or anti-DNA (25) primary antibody in PBS for $1 \mathrm{~h}$ at room temperature in a humidified chamber. Subsequently, the samples were washed three times in PBS and incubated with an affinity-purified fluorescein isothiocyanate-conjugated goat-anti-mouse immunoglobulin $\mathrm{G}$ secondary antibody (Organon Teknika) at a dilution of 1:20 in PBS for $1 \mathrm{~h}$ at room temperature in a humidified chamber. Samples were washed four times in PBS and then counterstained with $4^{\prime}$, 6-diamidino-2-phenylindole $\cdot 2 \mathrm{HCl}$ (Serva) by using a stock made at $1 \mathrm{mg} / \mathrm{ml}$. The cover slips were mounted in a medium consisting of $90 \%$ Kodak glycerol, $10 \%$ PBS, and 4\% (wt/vol) $n$-propylgallate $(\mathrm{pH} 8.5)$ and viewed with a Zeiss Photomicroscope II equipped with an HBO 100-W mercury light source.

Immunoelectron microscopy. Spheroplasts were suspended and pelleted in $0.5 \mathrm{ml}$ of a $2 \%$ melted agar (Difco) solution and centrifuged in an Eppendorf microcentrifuge. The pelleted samples were allowed to solidify at $4^{\circ} \mathrm{C}$ for 5 min. The sample pellets were removed from the microcentrifuge tube, diced into $1-\mathrm{mm}$ cubes, dehydrated with 7-min washes in 70 and $80 \%$ ethanol, and infiltrated in $100 \%$ LR White (hard grade; London Resin Co., Ltd.). The samples were placed in $100 \%$ LR White resin at room temperature for $2 \mathrm{~h}$, and then the LR White solution was changed and the specimens were left overnight in LR White at room temperature and changed to fresh embedding medium twice on the following day. The samples were then transferred to fresh LR White in 00 gelatin capsules. The blocks were hardened and cured at $55^{\circ} \mathrm{C}$ overnight. Thin sections were cut by using a diamond knife on a Reichert-Jung Ultracut-E ultramicrotome. Thin $(80-\mathrm{nm})$ sections were picked up on 300 -mesh gold grids.

For immunolabeling, grids were floated face down in $\mathrm{m}_{3} \mathrm{G}$ antibody (24) or D77 antibody (1) diluted 1:1 in Tris-buffered saline containing $20 \mathrm{mM}$ Tris (pH 7.6), $150 \mathrm{mM} \mathrm{NaCl}, 20 \mathrm{mM}$ sodium azide, and $1.0 \%$ Tween 20 at $4^{\circ} \mathrm{C}$ overnight in a humidified chamber. Before incubation with anti-ribonucleoprotein particle antibody 58 at a dilution of 1:7,500, sections were blocked in buffer containing $8 \%$ bovine serum albumin for $30 \mathrm{~min}$. On the following morning, the grids were equilibrated to room temperature and then washed for 15 min in Tris-buffered saline. The grids were then transferred to colloidal gold-conjugated goat anti-mouse or anti-human immunoglobulin G (10- or 15-nm-diameter gold particles; Janssen Life Sciences Products) diluted 1:20 in Tris-buffered saline for $1 \mathrm{~h}$ at room temperature. Before incubation, the diluted, colloidal gold-labeled antibody was spun in a microcentrifuge for $5 \mathrm{~min}$ at room temperature. After incubation, the grids were washed for $15 \mathrm{~min}$ in Tris-buffered saline and $10 \mathrm{~min}$ in water and counterstained with Reynolds lead citrate (43) and uranyl acetate. Samples were examined at 75 $\mathrm{kV}$ in a Hitachi $\mathrm{H}-7000$ transmission electron microscope.

Silver staining. LR White cell sections collected on gold grids were floated for $5 \mathrm{~min}$ at $55^{\circ} \mathrm{C}$ in a mixture that contained 1 volume of $2 \%$ gelatin in $1 \%$ formic acid and 2 volumes of $50 \%$ silver nitrate solution (32). Grids were rinsed in distilled water, immersed in $5 \%$ thiosulfate solution for $5 \mathrm{~min}$, and thoroughly rinsed in distilled water again. Some sections were then poststained in $2 \%$ aqueous uranyl acetate and lead citrate.

\section{RESULTS}

Standard electron microscopy and nucleolar silver staining. Thin (80-nm) sections of yeast spheroplasts embedded in LR White resin were stained with uranyl acetate and lead citrate, and the overall ultrastructure of 100 cells was examined. The nuclear envelopes in these preparations appeared in negative contrast because of the solubility of lipids in LR White resin (Fig. 1a). Most of the nuclei contained a lightstaining region and a dark-staining region (Fig. 1a). The percentage of the total nucleus occupied by each of these regions in each section varied depending upon the plane of section through the nucleus. The light-staining region has previously been shown to contain chromatin $(31,50)$. As in 


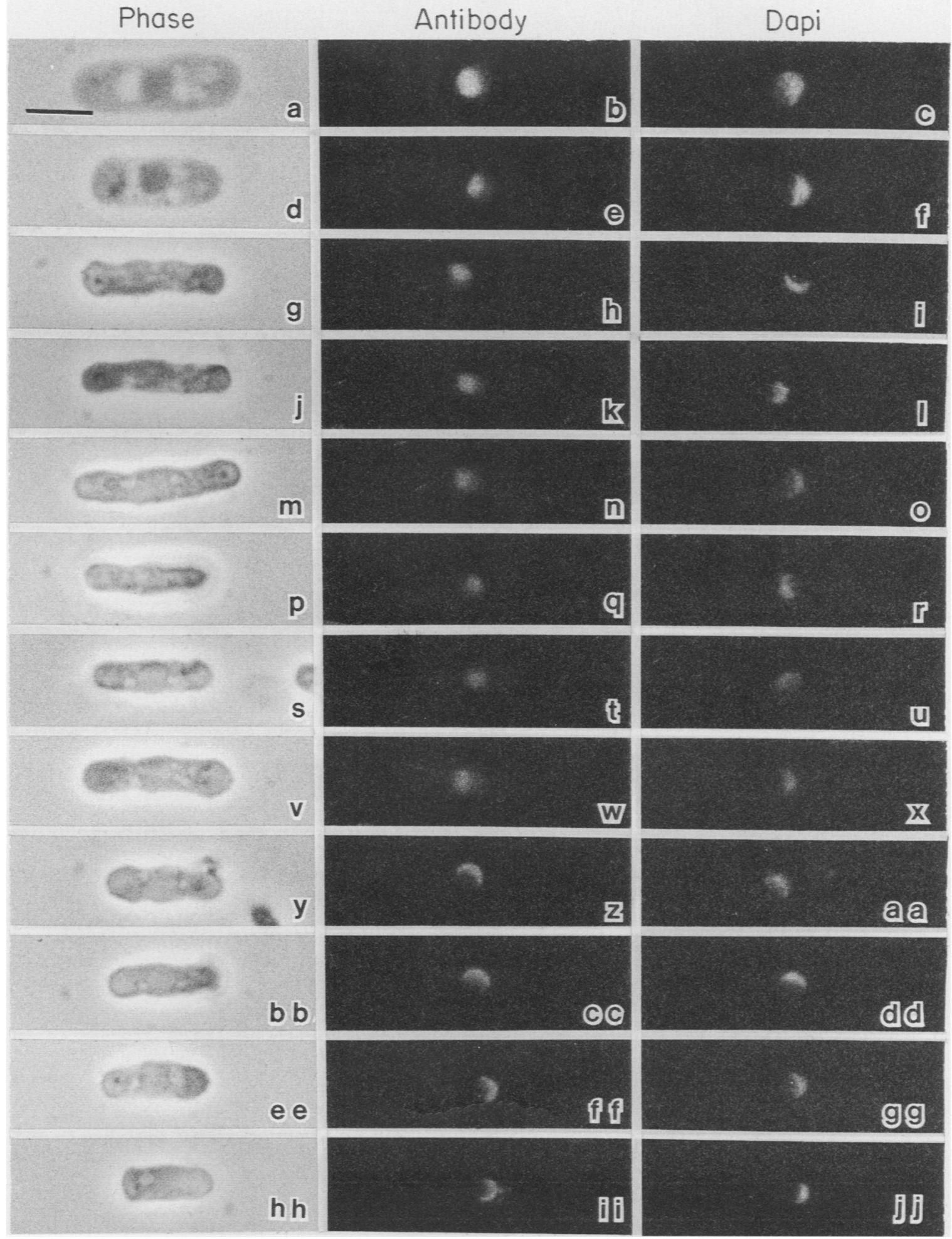

FIG. 2. Indirect immunofluorescence localization of snRNAs, nucleoli, and DNA. Immunofluorescence was performed with spheroplasts prepared from a wild-type strain of $S$. pombe by using a fluorescein-conjugated anti-mouse secondary antibody. Phase-contrast views (a, d, $\mathrm{g}, \mathrm{j}, \mathrm{m}, \mathrm{p}, \mathrm{s}, \mathrm{v}, \mathrm{y}, \mathrm{bb}, \mathrm{ee}$, and $\mathrm{hh}$ ) and immunofluorescence micrographs of cells labeled with anti-m $\mathrm{m}_{3} \mathrm{G}(\mathrm{b}, \mathrm{e}, \mathrm{h}$, and $\mathrm{k})$ to localize snRNAs, D77 (n, q, t, and w) to localize nucleoli, or anti-DNA antibody (z, cc, ff, and ii) and counterstained with 4',6-diamidino-2-phenylindole-2HCl to show the distribution of chromatin (c, f, i, l, o, r, u, x, aa, dd, gg, and ji) are shown. Bar, $5 \mu \mathrm{m}$. 

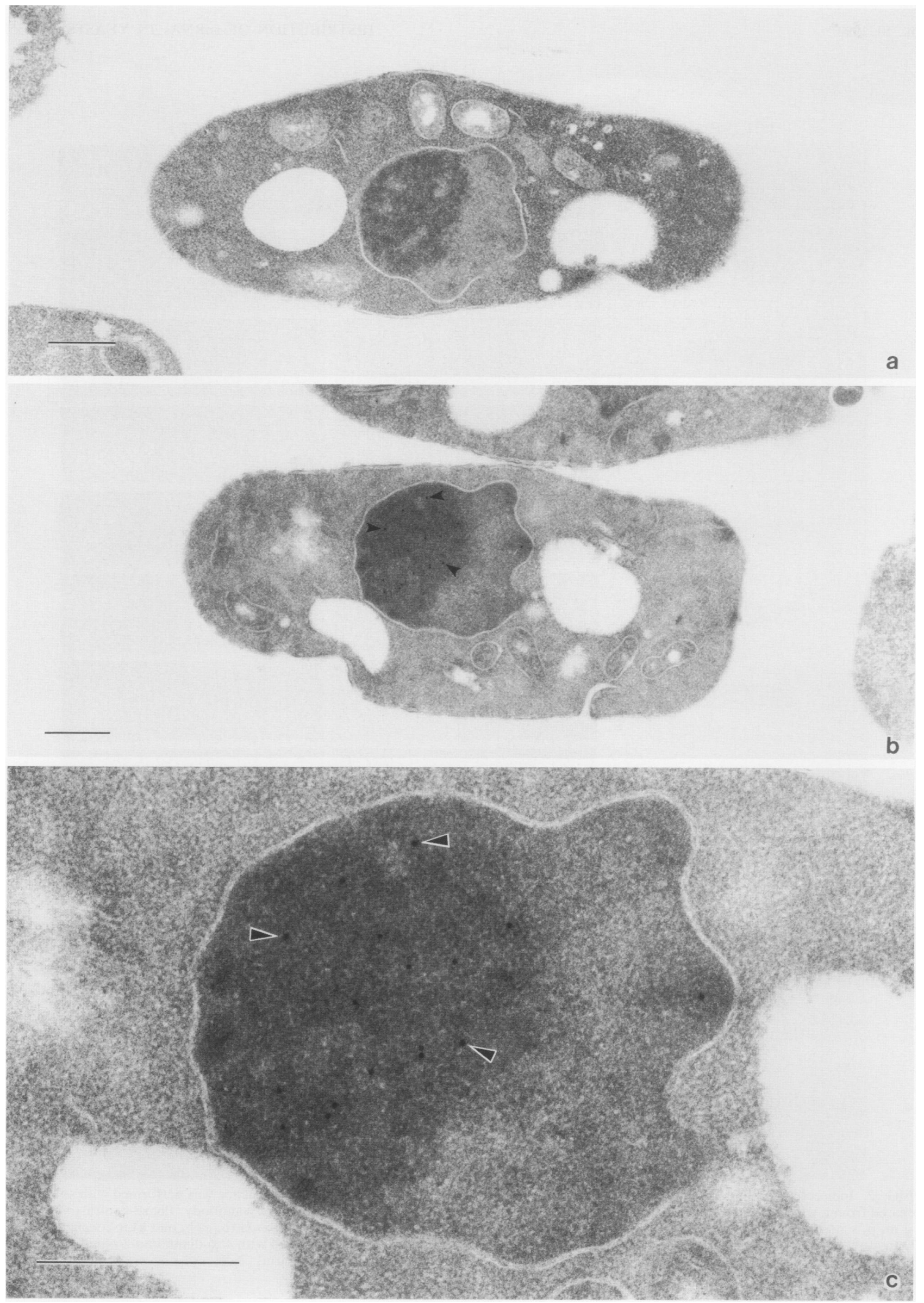
those studies, the chromatin appeared to be fairly uniform in appearance, with little to no condensed chromatin or heterochromatin (Fig. 1a). The dark-staining region of the $S$. cerevisiae nucleus has been suggested to contain rRNA precursors $(49,50)$. In our preparations, there appeared to be several (one to five) electron-lucid zones within the nucleolar region (Fig. $1 \mathrm{~b}$ and $\mathrm{c}$ ). These regions resembled fibrillar centers of mammalian cell nucleoli and were often surrounded by a region of greater electron density (Fig. 1c, arrows) which resembles the fibrillar component of mammalian cell nucleoli $(6,36)$. A similar staining pattern has previously been observed in the fission yeast $S$. japonicus var. versatilis (45) but has not been reported before in $S$. pombe. As a means to further evaluate the distribution of nucleolar components within the electron-dense region of the $S$. pombe nucleus, we used a nucleolus-specific silverstaining cytochemical technique on sections of cells embedded in LR White resin. With the silver-staining procedure, specific reactivity has been shown to occur at the nucleolusorganizing region of chromosomes during mitosis $(2,21,47)$ and at the fibrillar centers or fibrillar component of a variety of animal cell nucleoli $(2,8,9,19,20,36)$ during interphase. Silver-staining nucleolus-organizing region proteins have been described as acidic proteins $(21,22,35,59)$ whose presence is related to nucleolar transcriptional activity $(18$, 40). When the silver-staining procedure was applied to $S$. pombe cell sections, specific staining was observed within one part of the yeast cell nucleus (Fig. 1d). The staining formed a branched distribution pattern which coiled as it extended throughout one portion of the nucleus (Fig. 1d). The silver-stained regions often surrounded the less electron-dense fibrillar centers (Fig. 1e). This type of distribution pattern is very characteristic of the arrangement of the nucleolonema or fibrillar component reported in a variety of mammalian cell nucleoli. The nucleolonema is considered to correspond to the typical active rRNA transcription units observed upon chromosome spreading (13). To determine whether the silver staining was contained within the electron-dense or nucleolar portion of the $S$. pombe nucleus, sections were poststained with uranyl acetate and lead citrate after silver staining to impart contrast to the cell nucleus. When such sections were observed in the electron microscope, it was apparent that the silver-staining pattern was contained within the more electron-dense nucleolar portion of the nucleus (Fig. 1e).

Immunofluorescent localization of snRNAs. $S$. pombe spheroplasts were immunostained with an anti- $m_{3} G$ antibody (24) which recognizes the fission yeast homologs of $U 1$ to U5 snRNAs (3; A. Krainer and D. Frendewey, unpublished results). The snRNAs were localized to the nonchromatin or nucleolar portion of the nucleus (Figs. $2 b, e, h$, and k) as determined by double labeling with the fluorochrome 4', 6-diamidino-2-phenylindole $\cdot 2 \mathrm{HCl}$, which specifically binds to DNA (Fig. 2c, f, i, and l). To further confirm that the immunolabeled snRNAs were present in the nucleolar portion of the nucleus, a nucleolus-specific antibody was used on another series of samples. D77 is an antibody that recognizes a nucleolar protein of 38 kilodaltons $(\mathrm{kDa})$ in $S$. cerevisiae and has been shown to cross-react with $S$. pombe (1). D77 is thought to recognize the yeast homolog of fibrillarin, which is a protein found in the fibrillar region of the metazoan nucleolus and is associated with the nucleolusspecific U3 snRNP (1). Immunofluorescence microscopy of cells stained with the D77 antibody showed immunoreactivity in the nucleolar portion of the $S$. pombe nucleus (Fig. 2n, $\mathrm{q}, \mathrm{t}$, and $\mathrm{w}$ ), confirming its nucleolar composition. To rule out the possibility that the chromatin-enriched region of the nucleus is inaccessible to antibodies, we used a DNAspecific antibody, 2C10 (25), for immunofluorescence staining. As shown in Fig. $2 z, c c$, ff, and ii, the DNA antibody recognized the same region of the nucleus as the fluorochrome 4',6-diamidino-2-phenylindole-2 $\mathrm{HCl}$ (Fig. 2aa, dd, gg, and jj), which clearly demonstrates that antibodies can penetrate the chromatin-enriched portion of the nucleus.

Immunoelectron microscopy. To determine whether there are any snRNAs in the chromatin region that are not abundant enough to be detected by immunofluorescence, we used immunoelectron microscopy. To visualize the snRNAs at the electron microscopic level, we used monoclonal antibody $\mathrm{m}_{3} \mathrm{G}$ in combination with secondary antibodies coupled to colloidal gold. Control sections that were labeled only with the secondary antibody showed no gold staining (Fig. 3a). Sections of spheroplasts labeled with both the primary and secondary antibodies showed most of the gold particles in the nucleus and minimal background labeling in the cytoplasm (Fig. 3b). The gold particles located in the nucleus were concentrated in the electron-dense nucleolar region (Fig. 3c). The gold particles were counted in 50 individual spheroplasts to quantitate the distribution of snRNAs in yeast cells. The results showed that $85 \%$ of the gold particles were localized in the nucleolar region, $11 \%$ were present in the chromatin-enriched region, and $4 \%$ were present in the cytoplasm. Similar localization to the electrondense region of the nucleus was observed when an antibody with strong reactivity to a $34-\mathrm{kDa}$ U1 snRNP protein (S. Hoch, personal communication) designated A was used (Fig. 4).

To determine whether this distribution pattern of snRNAs was unique to $S$. pombe or was also found in the budding yeast, we examined the localization of snRNAs in $S$. cerevisiae. As in $S$. pombe, the snRNAs in $S$. cerevisiae were concentrated in the more electron-dense nucleolar region of the nucleus (Fig. 5). The lower number of antibody-linked colloidal gold particles found in the $S$. cerevisiae nucleus than in the $S$. pombe nucleus is consistent with the 10 -fold lower abundance of snRNAs in the $S$. cerevisiae nucleus (44, $60)$.

To further confirm the nucleolar origin of the electrondense nuclear region, thin sections were incubated with nucleolus-specific antibody D77, which has been shown to cross-react with $S$. pombe (1). Most of the gold particles were located within the dark-staining region of the nucleus (Fig. 6). The gold particles appeared to be dispersed throughout this region; however, neither the anti- $m_{3} \mathrm{G}$ antibody nor D77 was observed within the electron-lucid regions of the nucleolus, suggesting that the snRNAs and fibrillarin are not

FIG. 3. Immunoelectron microscopic localization of snRNAs in the $S$. pombe nucleus. Ultrathin sections of fission yeast embedded in LR White resin were incubated with anti- $m_{3} G$ primary antibody, followed by a 15-nm-diameter colloidal gold particle-conjugated secondary antibody and poststained for electron microscopy. Control cells not incubated with the primary antibody showed no gold labeling (a). Yeast cells stained with both the primary and secondary antibodies showed most of the gold particles in the nuclei (b). An enlarged view of the nucleus shows that most of the gold particles were present in the electron-dense portion (c). Arrowheads point to representative gold particles. Bars, $0.5 \mu \mathrm{m}$. 


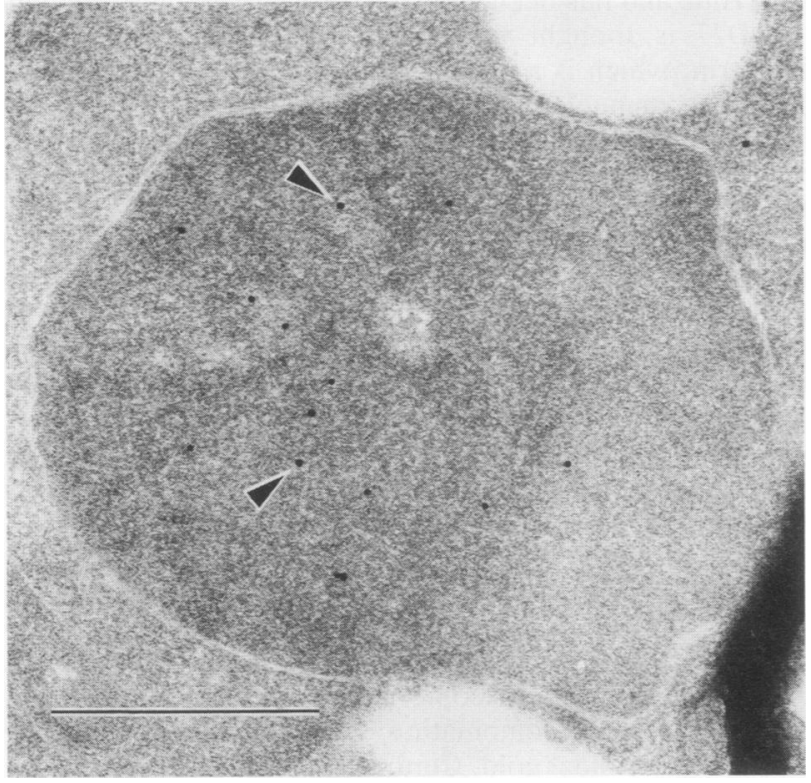

FIG. 4. Immunolocalization of snRNPs in the nucleus of the fission yeast $S$. pombe with an autoantibody which recognized the $\mathrm{A}$ protein of U1 snRNP. U1 snRNPs were concentrated in the electron-dense portion of the cell nucleus. Representative colloidal gold particles are identified by arrowheads. Bar, $0.5 \mu \mathrm{m}$.

located within these areas of the nucleolus. Twenty cells were counted to quantitate the distribution of D77 within yeast cells. Of the gold particles, $78 \%$ were located in the electron-dense nucleolar region, $10 \%$ were present in the chromatin-enriched region, and $13 \%$ were present in the cytoplasm. Interestingly, with the glutaraldehyde fixation conditions used in this study, the D77 epitope was not destroyed as it had been reported to be in an earlier study (1).

\section{DISCUSSION}

We localized the abundant snRNAs in wild-type strains of the fission yeast $S$. pombe by indirect immunofluorescence microscopy and immunoelectron microscopy. The results of these experiments showed that most of the snRNAs were present within the more electron-dense portion of the nucleus which has heretofore been referred to in the literature as the nucleolus. In addition, we found a similar localization of snRNAs in the nucleus of the budding yeast $S$. cerevisiae. These findings are in contrast to the results obtained with mammalian cells, in which most of the abundant snRNAs were present in a nonnucleolar network within the nonchromatin-containing regions of the nucleoplasm (53). Our results suggest that both structurally and functionally, the yeast nucleus needs to be reexamined, and perhaps classical designations of nuclear regions need to be modified to accommodate new data.

In mammalian cells, the nucleolus is a distinct biochemical and structural entity within which ribosomal genes and their products are naturally sequestered from the rest of the genome and nucleoplasm. Within this highly specialized non-membrane-bound region of the nucleus, ribosomal gene transcription, rRNA processing, and preribosomal particle formation occur (6). It is clear from previous studies with $S$. pombe that the electron-dense or nucleolar region of the nucleus contains an abundance of RNA and protein $(31,49)$. In Saccharomyces carlsbergensis, the $37 \mathrm{~S}$ and $28 \mathrm{~S}$ rRNA

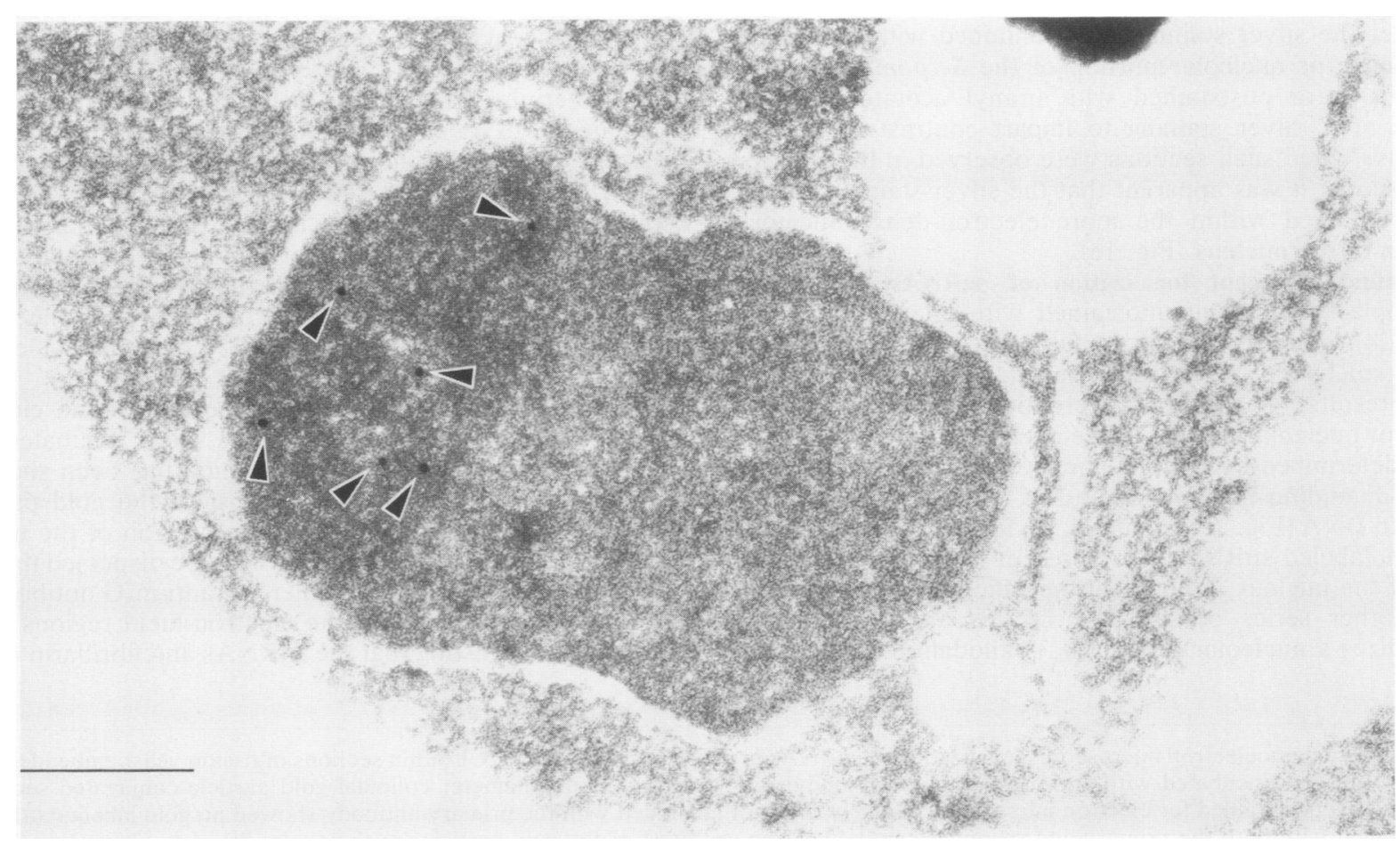

FIG. 5. Immunoelectron microscopic localization of snRNAs in the nucleus of the budding yeast $S$. cerevisiae with an $m_{3} G$ antibody. snRNAs were concentrated in the electron-dense portion of the cell nucleus (arrowheads). Bar, $0.5 \mu \mathrm{m}$. 

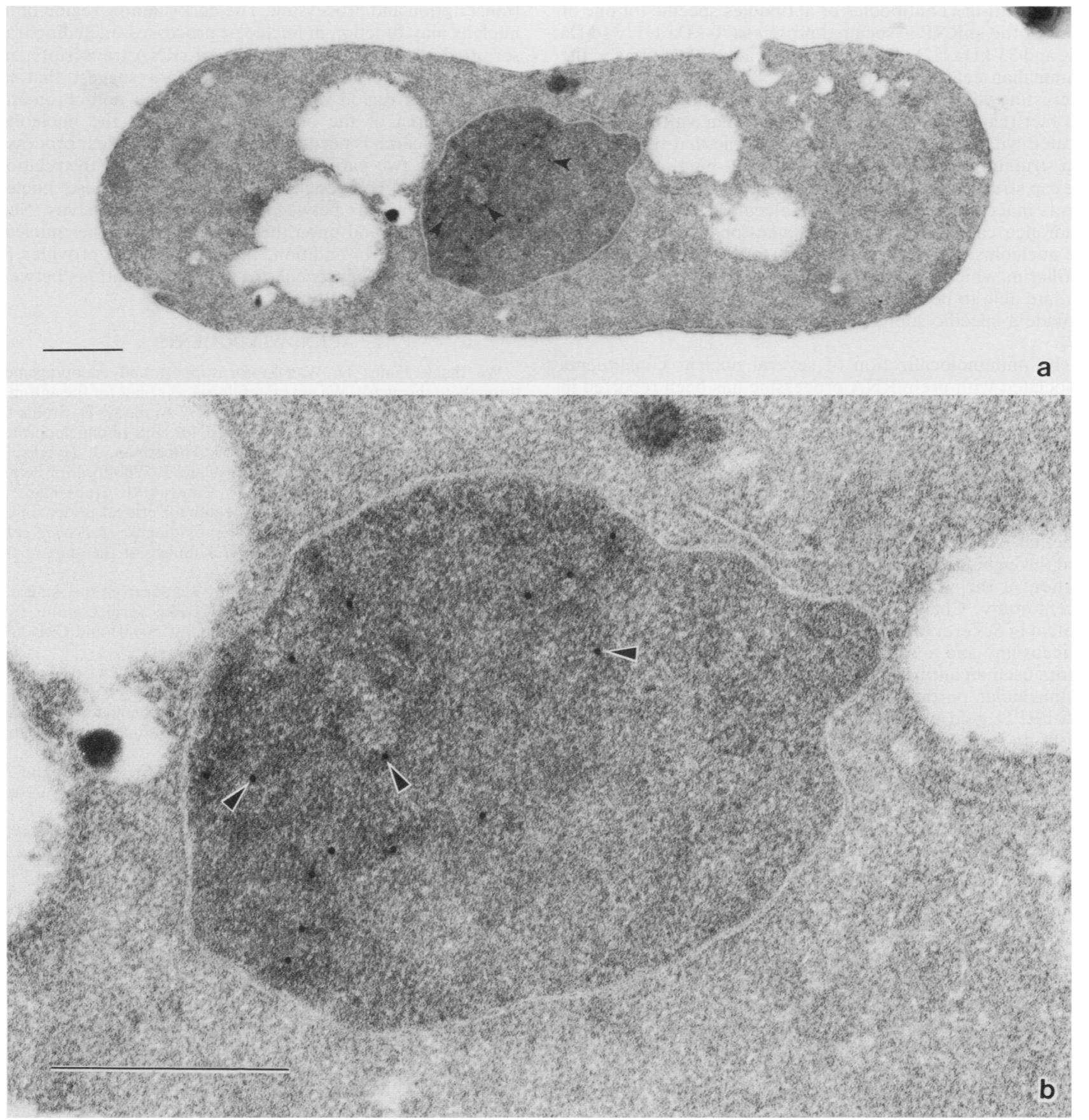

FIG. 6. Immunoelectron microscopic localization of a nucleolar protein in the $S$. pombe nucleus. Ultrathin sections of fission yeast embedded in LR White resin were incubated with antibody D77, followed by a colloidal gold-conjugated secondary antibody, and poststained for electron microscopy. Yeast cells stained with both the primary and secondary antibodies showed most of the gold particles in the dark-staining portion of the nucleus, identifying it as the nucleolar component of the nucleus. Arrowheads point to representative gold particles. Bars, $0.5 \mu \mathrm{m}$.

precursors are located within this region (50). Recently, Dvorkin et al. (10) have used electron microscopic in situ hybridization techniques to localize $25 \mathrm{~S}$ rDNA to the nucleolar region of the $S$. cerevisiae cell nucleus. In addition, the present study showed that nucleolus-organizing region-specific silver staining was localized to a portion of the electrondense region of the $S$. pombe nucleus. Therefore, at least a portion of the electron-dense region of the cell nucleus contained nucleolar components.
The localization of snRNAs and/or snRNPs in mammalian cells has been studied in a variety of laboratories, and it is generally agreed that these RNA molecules localize in a speckled immunostaining pattern within the nuclei of a variety of mammalian cells and tissues $(33,34,42,52,54)$. Recently, D.L.S. has used three-dimensional reconstruction techniques to demonstrate that these speckled areas connected and form a latticework or network within the nucleoplasm (53). In direct contrast to the present findings with $S$. 
pombe, anti- $\mathrm{m}_{3} \mathrm{G}$ antibodies or antibodies specific for one or more of the snRNP-associated proteins (70-kDa U1, 34-kDa $\mathrm{U} 1$, and 33-kDa U2) did not immunoreact with regions of the mammalian cell nucleolus $(42,52,58)$. This is particularly interesting with regard to $\mathrm{m}_{3} \mathrm{G}$-specific antibodies in light of the fact that a major mammalian nucleolar snRNA, U3, is located within the nucleolus. It is possible that the $\mathrm{U} 3 \mathrm{~m}_{3} \mathrm{G}$ cap structure is blocked by proteins that bind at or around the cap structure in vivo. Alternatively, it is possible that the cap is inaccessible to antibody molecules because of steric hindrance caused by its three-dimensional position within the nucleolus. However, antibodies to the nucleolar protein fibrillarin, which is a U3-specific nucleolar protein $(28,37$, 57), are able to penetrate the mammalian cell nucleolus and provide a specific subnucleolar immunolocalization pattern (37).

The immunolocalization of several nuclear constituents associated with pre-mRNA processing has been reported in the budding yeast $S$. cerevisiae. Last and Woolford (26) produced antibodies against fusion proteins that contain portions of the PRP2 or PRP3 open reading frames. These antibodies were used at the light microscopic level to show that polypeptides expressed from high-copy-number plasmids were localized to the cell nucleus in $S$. cerevisiae. Whether overexpressed PRP2 or PRP3 proteins were localized throughout the nucleoplasm or restricted to a particular portion of the yeast nucleus was not reported. In a more recent study, Chang et al. (7) have shown that the PRP11 protein in $S$. cerevisiae is specifically associated with the $40 S$ spliceosome and a $30 \mathrm{~S}$ complex. In addition, those investigators used an antibody to localize the PRP11 protein to the nonnucleolar portion of the $S$. cerevisiae nucleus. Of the anti-PRP11 gold particles, 52\% were localized in the cytoplasm and were regarded as nonspecific background staining, while $44 \%$ were localized in the nucleoplasm and were considered specific. In the present study, we used an antibody against the $\mathrm{m}_{3} \mathrm{G}$ cap structure of snRNAs, and upon quantitation, we observed that $85 \%$ of the $m_{3} \mathrm{G}$-labeled colloidal gold particles were localized to the nucleolar portion of the nucleoplasm, $11 \%$ were in the chromatin-enriched portion of the nucleoplasm, and $4 \%$ were in the cytoplasm. Brennwald et al. (3) have shown that this same $m_{3} G$ antibody immunoprecipitates snRNPs U1 to U5 from $S$. pombe extracts and $U 1$ and $U 2$ snRNPs are the most predominant snRNPs in this organism. In addition, we found a similar localization by using an antibody which recognizes a protein component of U1 snRNP. One possibility for the differential localization of snRNAs observed in the present study is that most of the snRNAs localized to the electron-dense region of the nucleus may represent potential sites of splicing complexes. Recently, Fu and Maniatis (14) have shown that a non-snRNP splicing factor in mammalian cells localizes within nuclear regions enriched in snRNPs. These findings support our original model (53) that the nuclear regions concentrated in snRNPs form a framework within which events involved in pre-mRNA processing take place or from which they emanate. If these findings are consistent in yeast nuclei, we predict that pre-mRNA splicing would occur in the electron-dense region of the yeast nucleus, where snRNAs are concentrated. On the basis of our findings that most snRNAs localized to the nucleolar portion of the yeast cell nucleus, we suggest a modification of the current model of the yeast nucleus. We propose that the classically designated nucleolar portion of the yeast nucleus is organized differently from the mammalian cell nucleolus and contains functional domains in addition to those associated with rRNA transcription and processing. The dark-staining region of the nucleus may function in nucleolar processes, including transcription of rDNA and processing of rRNA transcripts, and in pre-mRNA processing. We therefore suggest that the dark-staining region be referred to as the non-chromatinenriched area of the nucleus, rather than the nucleolus. Further research is needed to define which nuclear processes occur in the two parts of the yeast nucleus and the relationship between components within each of these nuclear regions, as well as between the regions themselves. Such studies will depend upon the localization of other nucleusspecific probes. In addition, the yeast system provides for powerful genetic approaches to define associations between nuclear structure and function.

\section{ACKNOWLEDGMENTS}

We thank James D. Watson for support and encouragement throughout this work. We are grateful to A. Krainer for the anti- $m_{3} G$ antibody, J. Aris and G. Blobel for the D77 antibody, D. Stollar for the anti-DNA antibody, and S. Hoch for anti-ribonucleoprotein particle autoantibody 58. We thank J. Huberman, J. Hyams, B. McClintock, M. Spector, D. Tollervey, and J. Woolford for helpful discussions. We are grateful to G. Conway, J. Huberman, A. Krainer, B. McClintock, and M. Spector for critical review of the manuscript. We thank A. Sutton for providing $S$. cerevisiae cells. The excellent technical assistance of J. Suhan at the start of this study is gratefully acknowledged.

This work was partially supported by a grant from the American Cancer Society (NP-619A) and Public Health Service grants from the National Institutes of Health (5P30 CA45508-03 and GM42694) to D.L.S.

\section{LITERATURE CITED}

1. Aris, J. P., and G. Blobel. 1988. Identification and characterization of a yeast nucleolar protein that is similar to a rat liver nucleolar protein. J. Cell Biol. 107:17-31.

2. Bourgeois, C. A., D. Hernandez-Verdun, J. Hubert, and $M$. Bouteille. 1979. Silver staining NORs in electron microscopy. Exp. Cell Res. 123:449-452.

3. Brennwald, P., G. Porter, and J. A. Wise. 1988. U2 small nuclear RNA is remarkably conserved between Schizosaccharomyces pombe and mammals. Mol. Cell. Biol. 8:5575-5580.

4. Busch, H. 1974-1984. The cell nucleus, vol. 1-10. Academic Press, Inc., New York.

5. Busch, H., R. Reddy, L. Rothblum, and Y. C. Choi. 1982. snRNAs, snRNPs, and RNA processing. Annu. Rev. Biochem. 51:617-654.

6. Busch, H., and K. Smetana. 1970. The nucleolus. Academic Press, Inc., New York.

7. Chang, T.-H., M. W. Clark, A. J. Lustig, M. E. Cusick, and J. Abelson. 1988. RNA11 protein is associated with the yeast spliceosome and is localized in the periphery of the cell nucleus. Mol. Cell. Biol. 8:2379-2393.

8. Daskal, Y., K. Smetana, and H. Busch. 1980. Evidence from studies on segregated nucleoli that nucleolar silver staining proteins C23 and B23 are in the fibrillar component. Exp. Cell Res. 127:285-291.

9. Dimova, R. N., D. V. Markov, K. C. Gajdardjieva, M. D. Dabeva, and A. A. Hadjiolov. 1982. Electron microscopic localization of silver staining NOR-proteins in rat liver nucleoli upon D-galactosamine block of transcription. Eur. J. Cell Biol. 28: 272-277.

10. Dvorkin, N., M. W. Clark, and B. A. Hamkalo. 1989. An approach to the analysis of nuclear organization in $S$. cerevisiae using EM in situ hybridization. J. Cell Biol. 109:6a.

11. Epstein, P., R. Reddy, and H. Busch. 1984. Multiple states of U3 RNA in Novikoff hepatoma nucleoli. Biochemistry 23:54215425.

12. Fakan, S., and D. Hernandez-Verdun. 1986. The nucleolus and the nucleolar organizer regions. Biol. Cell. 56:189-206.

13. Franke, W. W., H. Spring, M. F. Trendelenburg, and $H$. 
Zentgraf. 1979. Organization of nucleolar chromatin, p. 49-95. In H. Busch (ed.), The cell nucleus, vol. VII Academic Press, Inc., New York.

14. Fu, X.-D., and T. Maniatis. 1990 . Factor required for mammalian spliceosome assembly is localized to discrete regions in the nucleus. Nature (London) 343:437-441.

15. Goessens, G. 1984. Nucleolar structure. Int. Rev. Cytol. 87: 107-158.

16. Gordon, C. N. 1977. Chromatin behaviour during the mitotic cell cycle of Saccharomyces cerevisiae. J. Cell Sci. 24:81-93.

17. Hadjiolov, A. A. 1985. The nucleolus and ribosome biogenesis. Cell Biol. Monogr. 12:1-268.

18. Hansmann, I., J. Gebauer, L. Bihl, and T. Grimm. 1978. Onset of nucleolus organizer activity in early mouse embryogenesis and evidence for its regulation. Exp. Cell Res. 114:263-268.

19. Hernandez-Verdun, D., M. Derenzini, and M. Bouteille. 1982. The morphological relationship in electron microscopy between NOR-silver proteins. Chromosoma 85:461-473.

20. Hernandez-Verdun, D., J. Hubert, C. A. Bourgeois, and M. Bouteille. 1980. Ultrastructural localization of Ag-NOR stained proteins in the nucleolus during the cell cycle and in other nucleolar structures. Chromosoma 79:349-362.

21. Howell, X. M., T. E. Denton, and J. R. Diamond. 1975. Differential staining of the satellite regions of human acrocentric chromosomes. Experientia 31:260-262.

22. Hubbell, H. R., L. I. Rothblum, and T. C. Hsu. 1979. Identification of a silver binding protein associated with the cytological silver staining of actively transcribing nucleolar regions. Cell Biol. Int. Rep. 3:615-622.

23. Hubert, J., J. Bureau, and M. Bouteille. 1984. Anchorage of the nucleolus in the pore complex-lamina by a DNA-bearing structure masked in situ in rat liver nuclei. Biol. Cell 52:91-102.

24. Krainer, A. R. 1988. Pre-mRNA splicing by complementation with purified human U1, U2, U4/U6 and U5 snRNPs. Nucleic Acids Res. 16:9415-9429.

25. Kubota, T., T. Akatsuka, and Y. Kanai. 1986. A monoclonal anti-double stranded DNA antibody from an autoimmune MRL/ $\mathrm{Mp}$-lpr/lpr mouse: specificity and idiotype in serum immunoglobulins. Immunol. Lett. 14:53-58.

26. Last, R. L., and J. L. Woolford, Jr. 1986. Identification and nuclear localization of yeast pre-messenger RNA processing components: RNA2 and RNA3 proteins. J. Cell Biol. 103: 2103-2112.

27. Lerner, E. A., M. R. Lerner, C. A. Janeway, and J. A. Steitz. 1981. Monoclonal antibodies to nucleic acid-containing cellular constituents: probes for molecular biology and autoimmune disease. Proc. Natl. Acad. Sci. USA 78:2737-2741.

28. Lischwe, M. A., R. L. Ochs, R. Reddy, R. G. Cook, L. C. Yeoman, E. M. Tan, M. Reichlin, and H. Busch. 1985. Purification and partial characterization of a nucleolar scleroderma antigen $(\mathrm{Mr}=34,000 ; \mathrm{pI}, 8.5)$ rich in $\mathrm{N}^{\mathrm{G}}, \mathrm{N}^{\mathrm{G}}$-dimethylarginine. J. Biol. Chem. 260:14304-14310.

29. Luhrmann, R. 1988. snRNP proteins, p. 71-99. In M. L. Birnstiel (ed), Structure and function of major and minor small nuclear ribonucleoprotein particles. Springer-Verlag KG, Berlin.

30. McCully, E. K., and C. F. Robinow. 1971. Mitosis in the fission yeast Schizosaccharomyces pombe: a comparative study with light and electron microscopy. J. Cell Sci. 9:475-507.

31. Molenaar, I., W. W. Sillevis Smitt, T. H. Rozijn, and G. J. M. Tonino. 1970. Biochemical and electron microscopic study of isolated yeast nuclei. Exp. Cell Res. 60:148-156.

32. Moreno, F. J., R. M. Rodrigo, and G. Garcia-Herdugo. 1989. An experimental approach to nucleolar organization in plant cells: a morphological cytochemical and quantitative study. J. Cell Sci. 94:51-59.

33. Northway, J. D., and E. M. Tan. 1972. Differentiation of antinuclear antibodies giving speckled staining patterns in immunofluorescence. Clin. Immunol. Immunopathol. 1:140-154.

34. Nyman, U., H. Hallman, G. Hadlaczky, I. Pettersson, G. Sharp, and N. R. Ringertz. 1986. Intranuclear localization of snRNP antigens. J. Cell Biol. 102:137-144.

35. Ochs, R. L., and H. Busch. 1984. Further evidence that phos- phoprotein C23 $(110 \mathrm{kD} / \mathrm{pI} 5.1)$ is the nucleolar silver staining protein. Exp. Cell Res. 152:260-265.

36. Ochs, R. L., M. A. Lischwe, E. Shen, R. E. Carroll, and H. Busch. 1985. Nucleologenesis: composition and fate of prenucleolar bodies. Chromosoma 92:330-336.

37. Ochs, R. L., M. A. Lischwe, W. H. Spohn, and H. Busch. 1985. Fibrillarin: a new protein of the nucleolus identified by autoimmune sera. Biol. Cell 54:123-134.

38. Parker, K. A., and J. A. Steitz. 1987. Structural analyses of the human U3 ribonucleoprotein particle reveal a conserved sequence available for base pairing with pre-rRNA. Mol. Cell. Biol. 7:2899-2913.

39. Prestayko, A. W., M. Tonato, and H. Busch. 1970. Low molecular weight RNA associated with $28 \mathrm{~S}$ nucleolar RNA. J. Mol. Biol. 47:505-515.

40. Raman, R., and K. Sperling. 1981. Patterns of silver staining on NORs of prematurely condensed muntjac chromosomes following RNA inhibition. Exp. Cell Res. 135:373-378.

41. Reimer, G., K. M. Pollard, C. A. Penning, R. L. Ochs, M. A. Lischwe, H. Busch, and E. M. Tan. 1987. Monoclonal autoantibody from NZB/NZW F1 mouse and some human scleroderma sera target an $\mathrm{M}_{\mathrm{r}} 34,000$ nucleolar protein of the U3-ribonucleoprotein particle. Arthritis Rheum. 30:793-800.

42. Reuter, R., B. Appel, P. Bringmann, J. Rinke, and R. Luhrmann. 1984. 5'-Terminal caps of snRNAs are reactive with antibodies specific for 2,2,7-trimethylguanosine in whole cells and nuclear matrices. Exp. Cell Res. 154:548-560.

43. Reynolds, E. S. 1963 . The use of lead citrate at high $\mathrm{pH}$ as an electron-opaque stain in electron microscopy. J. Cell Biol. 17:208-212.

44. Riedel, N., J. A. Wise, H. Swerdlow, A. Mak, and C. Guthrie. 1986. Small nuclear RNAs from Saccharomyces cerevisiae: unexpected diversity in abundance, size and molecular complexity. Proc. Natl. Acad. Sci. USA 83:8097-9001.

45. Robinow, C. F., and J. S. Hyams. 1989. General cytology of fission yeasts, p. 273-330. In A. Nasim, P. Young, and B. F. Johnson (ed.), Molecular biology of the fission yeast. Academic Press, Inc., San Diego.

46. Robinow, C. R., and J. Marak. 1966. Fiber apparatus in the nucleus of the yeast cell. J. Cell Biol. 29:129-150.

47. Schwarzacher, H. G., A. V. Mikelsaar, and W. Schnedl. 1978. The nature of Ag-staining of nucleolus organizer regions. Electron and light microscopic studies on human cells in interphase, mitosis, and meiosis. Cytogenet. Cell Genet. 20:24-39.

48. Sharp, G. C., W. S. Irvin, E. M. Tan, R. G. Gould, and H. R. Holman. 1972. Mixed connective tissue disease-an apparently distinct rheumatic disease syndrome associated with a specific antibody to an extractable nuclear antigen (ENA). Am. J. Med. 52:148-159.

49. Sillevis Smitt, W. W., C. A. Vermeulen, J. M. Vlak, T. Rozijn, and I. Molenaar. 1972. Electron microscopic autoradiographic study of RNA synthesis in yeast nucleus. Exp. Cell Res. 70:140-144.

50. Sillevis Smitt, W. W., J. M. Vlak, I. Molenaar, and T. H. Rozijn. 1973. Nucleolar function of the dense crescent in the yeast nucleus. Exp. Cell Res. 80:313-321.

51. Smith, H. C., D. L. Spector, C. L. F. Woodcock, R. L. Ochs, and J. Bhorjee. 1985. Alterations in chromatin conformation are accompanied by reorganization of nonchromatin domains that contain U-snRNP protein p28 and nuclear protein p107. J. Cell Biol. 101:560-567.

52. Spector, D. L. 1984. Colocalization of U1 and U2 small nuclear RNPs by immunocytochemistry. Biol. Cell 51:109-112.

53. Spector, D. L. 1990. Higher order nuclear organization: 3dimensional distribution of small nuclear ribonucleoprotein particles. Proc. Natl. Acad. Sci. USA 87:147-151.

54. Spector, D. L., W. H. Schrier, and H. Busch. 1983. Immunoelectron microscopic localization of snRNPs. Biol. Cell 49:1-10.

55. Steitz, J. A., D. L. Black, V. Gerke, K. A. Parker, A. Kramer, D. Frendewey, and W. Keller. 1988. Function of the abundant U-snRNPs, p. 115-154. In M. L. Birnstiel (ed.), Structure and function of major and minor small nuclear ribonucleoprotein particles. Springer-Verlag KG. Berlin. 
56. Tanaka, K., and T. Kanbe. 1986. Mitosis in the fission yeast Schizosaccharomyces pombe as revealed by freeze-substitution electron microscopy. J. Cell Sci. 80:253-268.

57. Tyc, K., and J. A. Steitz. 1989. U3, U8 and U13 comprise a new class of mammalian snRNPs localized in the cell nucleolus. EMBO J. 8:3113-3119.

58. Verheijen, R., H. Kuijpers, P. Vooijs, W. Van Venrooij, and F. Ramaekers. 1986. Distribution of the 70k U1 RNA-associated protein during interphase and mitosis. J. Cell Sci. 86:173-190.

59. Williams, M. A., J. A. Kleinschmidt, G. Krohne, and W. W. Franke. 1982. Argyrophilic nuclear and nucleolar proteins of Xenopus laevis oocytes identified by gel electrophoresis. Exp. Cell Res. 137:341-351.

60. Wise, J. A., D. Tollervey, D. Maloney, H. Swerdlow, E. J. Dunn, and C. Guthrie. 1983. Yeast contains small nuclear RNAs encoded by single copy genes. Cell 35:743-751. 